\section{Transactional sex and HIV infection among commercial farm workers in South Africa}

\author{
Idris Durojaiye, ${ }^{1}$ \\ Nkechi Obisie-Nmehielle, ${ }^{2}$
}

Latifat Ibisomi ${ }^{1,3}$

${ }^{1}$ School of Public Health, University of the Witwatersrand, Johannesburg,

South Africa; ${ }^{2}$ International

Organization for Migration, Pretoria, South Africa; ${ }^{3}$ Nigerian Institute of Medical Research, Lagos, Nigeria

\section{Abstract \\ Background: High prevalence of HIV infection has been reported among commer- cial farm workers in South Africa, but stud- ies of the role of transactional sex in this epidemic is limited.}

Objective: This study seeks to examine the association between transactional sex and HIV infection among commercial farm workers in South Africa.

Methods: This is a cross-sectional secondary data analysis of the Integrated Biological and Behavioural Surveillance Survey by the International Organization of Migration among farm workers in Mpumalanga and Limpopo Provinces, South Africa in 2010. The study included 2,758 sexually active farm workers. The outcome variable was HIV infection while the main explanatory variable was engagement in transactional sex. Other explanatory variables were sex, age, marital status, number of sex partners, food security, recent history of sexually transmitted infection, condom use at last sex with non-regular partner, history of sexual violence and migration status. Bivariate and multivariable logistic regression analyses were done to obtain unadjusted and adjusted odds ratios of the association between transactional sex and HIV infection.

Results: Engagement in transactional sex was common (19\%) but not significantly associated with HIV infection (OR 1.1; CI 0.57-2.44). Female sex (1.93; 1.60-2.32), age 25 to 44 years, recent STI (OR 1.37; CI 1.18-1.58) and sexual violence (OR 1.39; CI 1.19-1.63) were significant risk factors for HIV infection.

Conclusion: Risky sexual behaviours were common among the farmworker population. HIV prevention interventions should include behavioural change communication and improved access to healthcare for STI and HIV treatment.

\section{Introduction}

Sub-Saharan Africa (SSA) is home to about 25.6 million of the global burden of 36.7 million people living with HIV. ${ }^{1}$ Over 60 percent of the population in SSA depend on farming for sustenance, ${ }^{2}$ and high HIV prevalence rates have been reported among agricultural communities in this region..$^{3-6}$ Over two-thirds of deaths from HIV/AIDS occur among people aged 15 to 49 years, ${ }^{1}$ therefore, the impact of the HIV epidemic on the agricultural sector, and by extension food security, may be profound due to loss of labour affecting the most agile and productive members of the rural community.

With an estimated HIV infection burden of about 7 million people in 2015, South Africa remains the country most affected by the epidemic worldwide. ${ }^{1}$ Despite declines in the incidence of HIV infection in the general population in South Africa due to an expansion of HIV prevention and treatment programs, HIV prevalence is still very high on commercial farms in the country. ${ }^{3,4} \mathrm{~A}$ 2010 report of the Integrated Biological and Behavioural Surveillance Survey (IBBSS) conducted in the Limpopo and Mpumalanga provinces of South Africa found that $39.5 \%$ of commercial farm workers tested positive for HIV, which was more than three times the national average prevalence of $12.14 \%$ at the time. ${ }^{7}$ It was also higher than the prevalence among key populations including disabled persons (16.7\%), high-risk alcohol drinkers (14.3\%) and recreational drug users $(12.7 \%) .^{7}$

This high rate of HIV infection is considered to be driven by a collective of several behavioural and sexual risk factors including multiple sexual partnership, sexual coercion, transactional sex, inconsistent use of condoms, age-disparate sexual relationships, presence of sexually transmitted infections (STIs), amongst others. ${ }^{4}$

One of the factors associated with the high prevalence of HIV infection among commercial farm workers is transactional sex. ${ }^{4-6,8}$ Transactional sex has been defined as "non-marital sexual relationship where men and women exchange sex for material possessions or favours such as money, clothing, transportation and school fees".,, 10 Although cash is the most commonly offered item in return for sex, other goods or services like housing, transport or employment could also be accepted. ${ }^{11,12}$ The participants in a transactional sexual relationship do not regard the practice as constituting commercial sex work or prostitution because the process of negotiation does not involve a pre-agreed value of exchange or fixed payment, but a varying range of favours or gifts could be given or
Correspondence: Idris Durojaiye, School of Public Health, University of the Witwatersrand, Johannesburg, South Africa. Tel: +2348033372692 .

E-mail: idrisdurojaiye@yahoo.com

Key words: Transactional sex, commercial farm workers, HIV infection.

Acknowledgements: the authors would like to thank the International Organization for Migration (IOM) for permission to use the data for this work.

Contributions: This paper is derived from the research report of the corresponding author for the award of MSc Epidemiology and Biostatistics degree by the University of the Witwatersrand, Johannesburg. All authors designed the study and secured the data for analysis. ID conceptualized the paper, analyzed the data and prepared the manuscript. LI and NOB reviewed the manuscript and supervised the corresponding author.

Conflict of interest: NOB works with the International Organization for Migration, Pretoria, South Africa, that provided the data used for this work.

Funding: None.

Received for publication: 23 August 2020

Revision received: 9 June 2020.

Accepted for publication: 18 January 2021.

This work is licensed under a Creative Commons Attribution NonCommercial 4.0 License (CC BY-NC 4.0).

(C) Copyright: the Author(s),2020

Licensee PAGEPress, Italy

Journal of Public Health in Africa 2020; 11:1229

doi:10.4081/jphia.2020.1229

accepted in return for sex. ${ }^{13}$ Conversely, in commercial sex work, the terms and conditions of the transaction are predetermined before the consummation of sex. ${ }^{14}$

Participants in transactional sex are motivated by a spectrum of reasons from a basic immediate desire to survive till the next meal on one extreme ('survival sex'), to purely undue covetousness for enhanced status in society, expensive clothing, exotic fashion accessories, automobiles and mobile phones ('consumption sex') on the other extreme in their quest for a middleclass lifestyle. ${ }^{11,12,15}$ The stereotype in most cultures in sub-Saharan Africa is that men are expected to express their masculinity in the form of money, gifts and favours to women, and women are expected to reciprocate these favours by giving sex in return. ${ }^{16}$ Therefore, men are often the givers 
of economic gifts or favours and in turn receive sexual favours from the woman in the relationship, ${ }^{16}$ even though a role reversal could occur in the case of "sugar mummies". ${ }^{15}$ Women in transactional sex relationships are likely to be young and single ${ }^{11}$, though older sugar mummies tend to have younger male partners they pay for sex. ${ }^{15}$

On commercial farms, both married and unmarried women have been reported to engage in transactional sex to augment their meagre income, obtain basic items (food and toiletries) and curry on-the-job favours to enhance their job security. ${ }^{6}$ The effect of transactional sex on HIV infection is more profound in women than men, with women having more than twice the risk of being infected compared with men among people who engage in transactional sex. ${ }^{14,17,18}$

Transactional sex is linked with risky sexual behaviours that increase vulnerability to HIV infection such as such as sex when drunk or with drugs, ${ }^{19,20}$ poor condom use, multiple sexual partnerships or relationship with a man with multiple sexual partners. ${ }^{10,15}$ Transactional sex is associated with adverse sexual health consequences including sexually transmitted infections and sexual violence. ${ }^{11}$ The association between transactional sex and these adverse outcomes may be mediated by the economic and power inequalities associated with transactional sex, especially among women. Women in transactional sex relationships are usually on the receiving end of power inequality in relationships and are thus incapable of negotiating safer sex practices like condom use. They are also likely to have multiple sexual partners in order to maximize their economic gain. ${ }^{11,15}$ Furthermore, these women are more prone to suffer violence from their intimate partners which in turn increases the risk of HIV infection. ${ }^{21}$

Through well-established biological mechanisms, sexually transmitted infections (STIs) increase the risk of acquiring or transmitting HIV infection by causing a breach of the otherwise protective mucosal barriers and increase the number of immune cells mobilized to the site of the lesion. ${ }^{22}$ This facilitates HIV transmission across these broken barriers and uptake of HIV by the immune cells. Studies have shown persons with coexisting chlamydia and herpes simplex virus-2 (HSV-2) infection have increased risk of HIV infection. ${ }^{23}$

There is a significant number of migrants on commercial farms in South Africa, predominantly from neighbouring countries of Zimbabwe, Mozambique, Botswana and Lesotho. ${ }^{24}$ Because of long periods of separation from spouses, family and community, migrants are prone to feel- ing isolated and anxious due to lack of family and communal support. They are thus likely to engage in risky sexual behaviour like multiple concurrent casual sexual partnerships, poor condom use with non-regular partners, sex while drunk, drug abuse and patronage of commercial sex workers. , $20,25^{2}$

Male migrants who are financially stable are more likely to have multiple sexual contacts and engage in transactional sex. ${ }^{8}$ With better incomes comes increased ability to pay for sex and maintain multiple sexual partners. Conversely, migrants who are food-insecure or unemployed are more likely to be consumers of transactional sex in return for money or favours including a job. ${ }^{20}$ They are also more likely to maximize the economic gain of transactional sex by keeping multiple sexual partners with the resultant effect of increased STIs and HIV infection. ${ }^{27}$

Despite the increasingly recognized role of transactional sex as a driver of HIV infection, there is limited study on its association with HIV infection among the commercial farm worker population in South Africa. This study attempts to bridge this gap by examining the relationship between transactional sex and HIV infection among commercial farm workers in two regions of South Africa.

\section{Materials and Methods}

\section{Study design}

This study is a cross-sectional secondary data analysis of farm workers from 23 commercial farms in the Malelane area of Mpumalanga Province and the Tzaneen and Musina areas of Limpopo Province, South Africa.

\section{Data source}

The data for this study was obtained from the Integrated Biological and Behavioural Surveillance Survey (IBBSS), which was conducted between March and May 2010 by the International Organization of Migration (IOM). The IBBSS sampled workers from 23 commercial farms in three areas in Limpopo and Mpumalanga Provinces of South Africa. The main purpose of the IBBSS was to obtain baseline information about the prevalence of HIV among farm workers and their behaviours and attitudes to guide tailored intervention for HIV prevention, treatment and care among commercial farm workers. All the surveyed commercial farms were involved in the Ripfumelo Project implemented by the International Organization for Migration. The aim of the project was to deliver HIV prevention and care to about 20,000 employees on 120 commercial farms.

\section{Study population, sample size and sampling method}

The population for this study included 2,758 commercial farm workers who had ever had sex and were employed either on a permanent or contract basis on the 23 farm settlements in the Malelane area of Mpumalanga Province and the Tzaneen and Musina areas of Limpopo Province, South Africa in 2010. Those who had never engaged in sexual intercourse were excluded from this study. The initial study comprised of 2,810 farm workers. However, after excluding those who had never had sex, the total study population was reduced to 2,758 farm workers.

Based on a previous study that reported a HIV prevalence of $28.5 \%$ among farm employees, ${ }^{3}$ the primary investigators assumed a HIV prevalence of $30 \%$ among this population, and a $2 \%$ precision at $95 \%$ confidence interval. The minimum sample size required was 2,017. However, a total 2,810 participants were interviewed out of which 2,798 had complete data. This study utilized data from all respondents in the primary study. The analysis sample in this study was 2,758. Based on the minimum sample size of 2,017 calculated for the primary study, the sample size of 2,758 used in this study is adequate.

This study utilized data obtained from all participants of the IBBSS who had ever had sex. The primary study employed a multistage cluster sampling method to select individual farms and farm workers from each of the selected farms. ${ }^{4}$ All participating farms were included in the survey and in each farm, a list of all workers was obtained including the section where they worked (for example picking, packing and laboratory). A proportionate number of workers were then sampled from each of these sites to make up the predetermined sample size for each farm. Batches of 10 workers were invited to listen to an introductory talk before deciding to participate. Those who chose to participate completed a questionnaire and gave finger-prick dried blood spot (DBS) samples for HIV testing. The response rate was over 98 percent, as measured by the number of attendees who gave DBS samples.

\section{Definition of variables}

The outcome variable was HIV infection, a dichotomous variable. It was categorized as 'positive' or 'negative' based on the result from the DBS sample of each participant. Engagement in transactional sex was 
the main explanatory variable and was defined as receiving or giving money, gifts, job, accommodation or transport in exchange for sex. It was a composite variable created from participants' responses to four questions on whether they had given or received (i) money or gifts, (ii) job, (iii) accommodation or (iv) transport, in exchange for sex.

Other explanatory variables included marital status, multiple sexual partnerships (defined as having more than one sexual partner in the past 12 months preceding the survey, food security (derived from responses to the question "I always have sufficient money to buy food for myself"), recent history of sexually transmitted infection (derived from responses to two questions - "In the past three months, have you had sores on your penis or vagina?" and "In the past three months, have you had an unusual discharge from your penis or vagi$n a$ ?"). Others are condom use at last sex with non-regular partner (based on the question "Did you use a condom the last time you had sex with your non-regular partner?"), recent history of sexual violence (the question asked was "In the past 12 months, have you been forced to have sex against your will?") and migration status (derived from citizenship - South African citizens were categorised as "non-migrants" while citizens of other countries were categorised as "migrants").

\section{Data analysis}

The data was analyzed using Stata 14 statistical software (StataCorp. 2015. Stata Statistical Software: Release 14. College Station, TX: StataCorp LP). It was checked for completeness, duplication and consistency. Statistical significance was indicated at the $95 \%$ confidence interval level. The design effect due to recruitment of participants from three farming areas was addressed using the survey (svy) command. A description of the socio-demographic and sexual behavioural characteristics of the study population was done and prevalence of HIV by the selected characteristics estimated. Univariable and multivariable logistic regression analyses were done to examine the relationship between transactional sex and HIV infection.

\section{Ethical considerations}

Permission to use the data was obtained from the International Organization for Migration. Ethical clearance to conduct this study was obtained from the University of the Witwatersrand vide its Human Research Ethics Committee (Medical) Clearance Certificate No. M170848. Participation in the IBBSS was voluntary and informed consent was obtained from respondents prior to anonymous testing of their blood samples for HIV.

\section{Results}

The following analysis is based on 2,758 respondents who reported ever having sex from a total of 2,798 farmworkers who participated in the IBBSS survey and had a HIV result. Table 1 displays the sociodemographic and sexual behavioural characteristics of the study population. Forty percent were living with HIV and about one in five respondents admitted engaging in transactional sex $(19 \%)$. Over half of the study sample were females $(55 \%)$ and the mean age of respondents was 35 years. Even though most respondents were married $(60 \%)$, engagement in multiple sexual partnerships was common (41\%) and food insecurity was high (48\%). Recent history of sexually transmitted infection was reported by $15 \%$ of the respondents and non-use of condom during last sex with a non-regular partner was high (44\%). Thirteen percent of respondents experienced sexual violence recently and migrants constituted $39 \%$ of the total study sample.

Table 2 shows the HIV prevalence by sociodemographic and sexual behavioural characteristics of the respondents. There was higher prevalence of HIV among those who engaged in transactional sex compared with those who did not (43\% vs 39\%). Almost half of the females were HIV positive $(47 \%)$ compared with about a third of the males (32\%). Respondents aged $30-39$ years had the highest HIV prevalence (over $50 \%$ ), while those 25 years and younger had the lowest prevalence (29\%). Married farm workers were less likely to be living with HIV (37\%) compared with farm workers who were never married (45\%) or formerly married (47\%).

Respondents who recently engaged in multiple sexual partnerships had higher HIV prevalence than those who did not (43\% vs $38 \%$ ). Food security did not appear to be protective against HIV infection as those who felt food secure had a slightly higher HIV prevalence than those who did not ( $41 \%$ vs $39 \%$ ). Respondents with recent history of sexually transmitted infection had higher prevalence of HIV compared with those who did not (49\% vs 39\%). Similarly, higher prevalence of HIV infection was recorded among those with recent history of sexual violence compared with those without (47\% vs $39 \%)$. Using a condom at last sex with a non-regular partner did not seem to confer protection against HIV infection as similar prevalence of HIV was observed between those who used a condom and those who did not at last sex with a nonregular partner $(40 \%)$. Prevalence of HIV infection was slightly higher among nonmigrants compared with migrants $(41 \%$ vs $38 \%)$.

\section{Association between transactional sex and HIV infection}

Table 3 shows the unadjusted and adjusted models of the association of transactional sex and other exposure variables with HIV infection. The univariable analyses in Column 2 show that being female (1.90; 1.63-2.23), aged between 25 and 44 years, recent multiple sexual partners (OR $1.18 ; 1.01-1.38)$, recent history of sexually transmitted infection (OR 1.57; CI 1.26$1.94)$ and recent history of sexual violence (OR 1.39; CI 1.10-1.75) were significantly associated with HIV infection.

Table 1. Sociodemographic and sexual behavioural characteristics of commercial farm workers from IOM's IBBSS study in Mpumalanga and Limpopo, South Africa, $2010(n=2,758)$.

\begin{tabular}{lc} 
HIV Infection & $\mathrm{N}^{\mathrm{a}}(\%)$ \\
Negative & \\
$\quad$ Positive & $1654(60)$ \\
Engagement in transactional sex & $1104(40)$ \\
$\quad$ No & $2221(81)$ \\
Yes & $530(19)$ \\
\hline Sex & \\
Male & $1242(45)$ \\
Female & $1511(55)$ \\
Age & \\
Mean (SD) & $35.3( \pm 10.6)$ \\
\hline Marital status & \\
Never married & $953(35)$ \\
$\quad$ Married & $1649(60)$ \\
Formerly married & $133(5)$ \\
Recent multiple sexual partnerships & \\
No & $1612(59)$ \\
Yes & $1105(41)$ \\
\hline Food security & \\
Yes & $1399(52)$ \\
No & $1304(48)$ \\
Recent history of sexually & \\
transmitted infection & \\
No & \\
Yes & $2329(85)$ \\
\hline & $398(15)$ \\
\hline
\end{tabular}

Condom use at last sex with

non-regular partner

$\begin{array}{lr}\text { Yes } & 1525(56.2) \\ \text { No } & 1189(43.81)\end{array}$

$\begin{array}{lc}\text { Recent history of sexual violence } & \\ \text { No } & 2337(87) \\ \text { Yes } & 335(13)\end{array}$

\begin{tabular}{ll} 
Migration status $^{\mathrm{c}}$ & \\
Non-Migrant & $1651(61)$ \\
Migrant & $1072(39)$ \\
\hline
\end{tabular}

aThe totals vary due to missing values. 'Respondents' answer to "I always have sufficient money to buy food for myself". ' 'Nonmigrant $=$ South African citizens; migrant $=$ non-South African citizens. $\mathrm{SD}=$ standard variation 
In the multivariable model displayed in Column 3, after controlling for other factors, respondents that were female (OR 1.93; 1.61-2.32), were aged 25 to 44 years, had multiple sexual partners (OR 1.20; CI 1.00$1.44)$, had a recent history of sexually transmitted infection (OR 1.39; CI 1.09-1.77) or experienced sexual violence recently (OR 1.37; CI 1.05-1.78) were significantly more likely to be HIV positive. Although respondents that engaged in transactional sex were more likely to be HIV positive, the association was not statistically significant in both univariable and multivariable models.

\section{Discussion}

This study examined the prevalence of transactional sex, as reported by study participants, and its association with HIV infection among commercial farm workers in the Limpopo and Mpumalanga Provinces of South Africa. We found that while engagement in transactional sex seemed high (19\%), it was not significantly associated with HIV infection in this population. This contrasts with other studies that showed significant association between transaction sex and HIV infection among agricultural populations in Kenya and Malawi. 28,29

The demographics of our population may explain this disparity in findings. Age of exposure to transactional sex has been shown to be an important risk factor for HIV infection. ${ }^{30}$ Engagement in transactional sex at an earlier age (approximately less than 20 years) was found to be associated with higher risk of HIV infection in women. More than 70 percent of the respondents in our study were older than 25 years and this may explain why the effect of transactional sex on HIV infection in this population was not significant.

The females in this study were almost twice as likely to be HIV infected as the males and conforms with the gender distribution of HIV infection in the South African general population and among agricultural workers in Kenya. ${ }^{5}$

Our study affirms the recognized association between HIV infection and multiple sexual partnerships. Multiple sexual partnerships increase the risk of HIV infection because individuals in such relationships are inadvertently connected to extensive sexual networks that raises their chances of exposure to persons living with HIV. ${ }^{7}$ The finding of a significant association between STI and HIV infection in this study is consistent with established behavioural and biological link between STIs and HIV infection. 22,23
The increased risk of HIV infection associated with sexual violence in this the study is also consistent with studies elsewhere. ${ }^{21}$ Violent sex is linked with low condom use and inability to negotiate safe sex and the bruising of skin and mucous membranes that accompanies forceful penetration during violent sex further facilitates viral transmission from perpetrator to victim and vice versa.

Though poor condom use at last sex with a non-regular partner was common in this population, it was not significantly associated with HIV infection, contrary to other studies that found increased susceptibility to HIV infection with poor condom use. ${ }^{31,32}$ This may be because the question asked, "Did you use a condom the last time you had sex with your non-regular partner?", did not adequately capture consis- tency of condom use. Consistency of condom use could be better measured by asking respondents whether they used condom all the time with all non-regular partners in the past 12 months.

The major strengths of this study are the relatively large sample size and the high response rate among participants. Furthermore, data from this study provides a baseline upon which future patterns of HIV and sexual behaviours on farming communities can be studied.

This study is limited by the lack of information about the timing of transactional sex in relation to HIV infection, thus the findings may suffer from temporality bias. Also, the effect of frequency of engagement in transactional sex on prevalence of HIV infection could not be explored as data on number of transactional sex encounters was

Table 2. HIV prevalence by sociodemographic and sexual behavioural characteristics of commercial farm workers from IOM's IBBSS study in Mpumalanga and Limpopo, South Africa, $2010(n=2,758)$.

\begin{tabular}{|c|c|c|c|}
\hline & $\begin{array}{l}\text { HIV - } \\
\mathrm{N}^{\mathrm{a}}(\%)\end{array}$ & $\begin{array}{l}\text { HIV + } \\
\mathrm{N}^{\mathrm{a}}(\%)\end{array}$ & P-value \\
\hline $\begin{array}{l}\text { Engagement in transactional sex } \\
\text { No } \\
\text { Yes }\end{array}$ & $\begin{array}{l}1350(61) \\
303(57)\end{array}$ & $\begin{array}{l}872(39) \\
231(43)\end{array}$ & 0.09 \\
\hline $\begin{array}{l}\text { Sex } \\
\quad \text { Male } \\
\quad \text { Female }\end{array}$ & $\begin{array}{l}849(68) \\
803(53)\end{array}$ & $\begin{array}{c}<0.001 \\
393(32) \\
708(47)\end{array}$ & \\
\hline $\begin{array}{l}\text { Age } \\
\quad<25 \\
25-29 \\
30-34 \\
35-39 \\
40-44 \\
>44\end{array}$ & $\begin{array}{l}315(71) \\
307(58) \\
218(47) \\
208(48) \\
203(64) \\
403(70)\end{array}$ & $\begin{array}{c}<0.001 \\
129(29) \\
221(42) \\
248(53) \\
221(52) \\
116(36) \\
169(30)\end{array}$ & \\
\hline $\begin{array}{l}\text { Marital status } \\
\text { Never married } \\
\text { Married } \\
\text { Formerly married } \\
\end{array}$ & $\begin{array}{c}531(55) \\
1039(63) \\
70(53)\end{array}$ & $\begin{array}{l}427(45) \\
610(37) \\
63(47) \\
\end{array}$ & $<0.001$ \\
\hline $\begin{array}{l}\text { Recent multiple sexual partnerships } \\
\text { No } \\
\text { Yes }\end{array}$ & $\begin{array}{l}992(62) \\
635(57)\end{array}$ & $\begin{array}{l}620(38) \\
470(43)\end{array}$ & 0.03 \\
\hline $\begin{array}{l}\text { Food security } \\
\text { Yes } \\
\text { No }\end{array}$ & $\begin{array}{l}823(59) \\
800(61)\end{array}$ & $\begin{array}{l}579(41) \\
506(39)\end{array}$ & 0.18 \\
\hline $\begin{array}{l}\text { Recent history of sexually transmitted infection } \\
\text { No } \\
\text { Yes }\end{array}$ & $\begin{array}{l}1434(61) \\
202(51)\end{array}$ & $\begin{array}{l}898(39) \\
198(49)\end{array}$ & $<0.001$ \\
\hline $\begin{array}{l}\text { Condom use last sex with non-regular partner } \\
\text { Yes } \\
\text { No }\end{array}$ & $\begin{array}{l}885(60) \\
749(60)\end{array}$ & $\begin{array}{l}584(40) \\
507(40)\end{array}$ & 0.87 \\
\hline $\begin{array}{l}\text { Recent history of sexual violence } \\
\text { No } \\
\text { Yes }\end{array}$ & $\begin{array}{l}1428(61) \\
178(53)\end{array}$ & $\begin{array}{l}912(39) \\
158(47)\end{array}$ & 0.005 \\
\hline $\begin{array}{l}\text { Migration status } \\
\text { Non-Migrant } \\
\text { Migrant }\end{array}$ & $\begin{array}{l}971(59) \\
660(62)\end{array}$ & $\begin{array}{l}683(41) \\
413(38)\end{array}$ & 0.15 \\
\hline
\end{tabular}

HIV- = HIV negative. HIV+ = HIV positive. aThe totals vary due to missing values. bRespondents' answer to "I always have sufficient money to buy food for myself". cNon-migrant $=$ South African citizens; migrant $=$ non-South African citizens . 
Table 3. Unadjusted and adjusted odds ratios (OR) and 95\% confidence intervals (CI) of association between transactional sex and HIV infection among commercial farm workers from IOM's IBBSS study in Mpumalanga and Limpopo, South Africa, 2010 (n = 2,758).

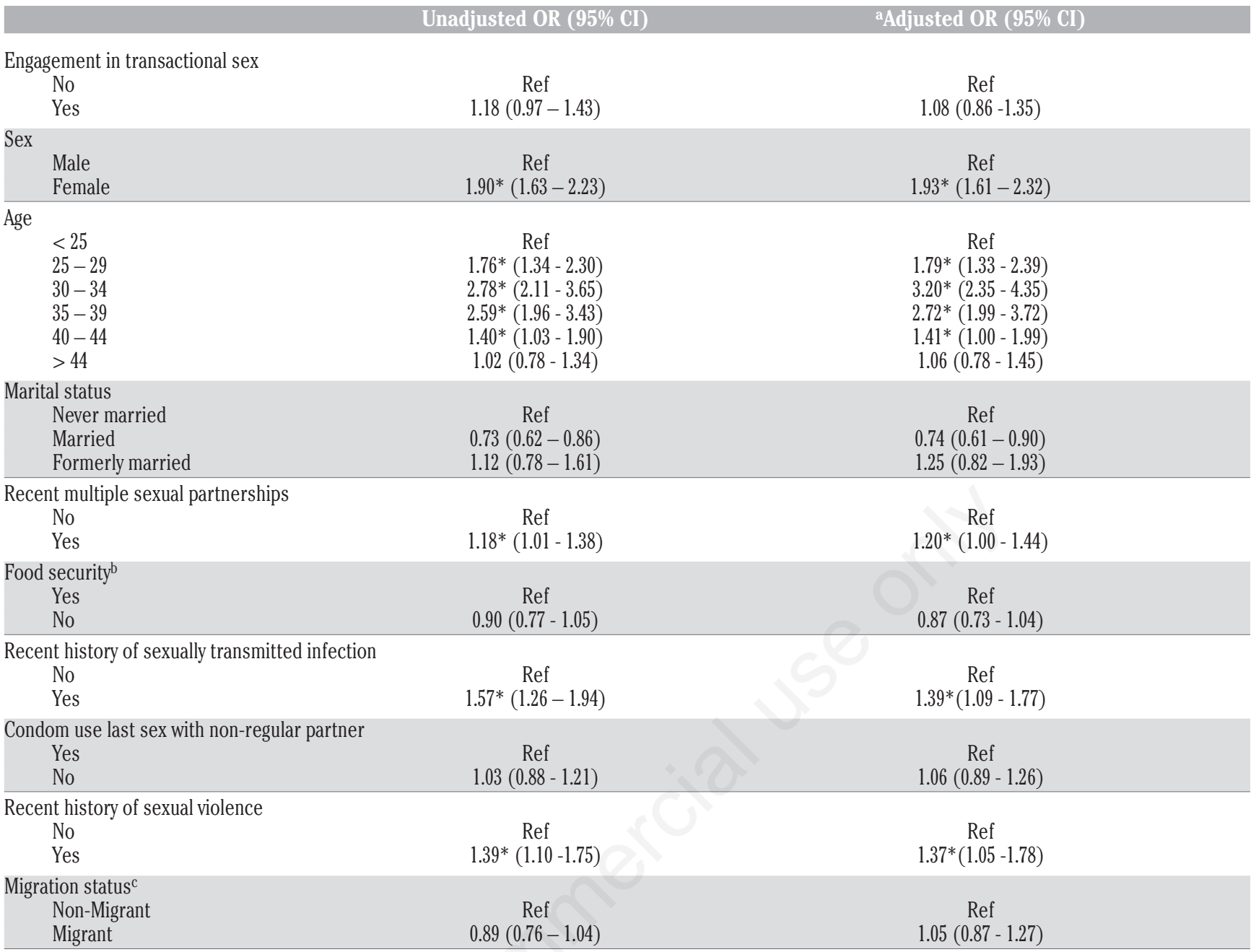

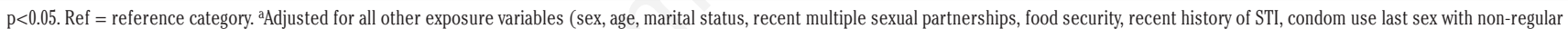

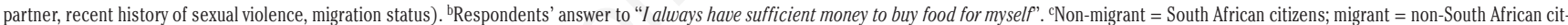
izens.

not collected. It has been shown that the risk of HIV infection among women in transactional sex relationships increases with frequency of receipt of money and/or gifts, attributable to greater frequency of sexual encounters that exposes them to HIV and STIs. ${ }^{30}$ There was inadequate data to distinguish between giving or receiving money, gifts or favours in exchange for sex, therefore the direction of transactional sex could not be determined. The receivers of material favours in transactional sex relationships are usually powerless to negotiate safe sex, are more likely to have multiple sexual partners to maximize economic gain and are prone to suffer sexual violence from intimate partners. These factors increase their risk of HIV infection. ${ }^{11,15}$ The gender dynamics of sexual violence could also not be explored because similar prevalence of sexual violence was reported for both male and female respondents and information was not collected to distinguish between perpetrators and victims of sexual violence. Lastly, internal (rural-urban, rural-rural) migrants were not differentiated from international (cross-border) migrants as information about place of origin within South Africa was not collected.

\section{Recommendations}

Our findings of high prevalence of HIV infection and risky sexual behaviours among the farmworker population highlights the need for a suite of HIV prevention programmes including:

1. Behavioural change interventions like sex education and counselling aimed at reducing the number of sexual partners and encouraging consistent and correct use of male and female condoms.

2. Increased farmworker access to healthcare to improve testing and treatment of sexually transmitted infections, use of antiretroviral medicines as pre-exposure prophylaxis (PrEP) and treatment of people living with HIV to reduce viral load and transmission of infection (treatment as prevention).

3. Strengthening the criminal justice system to promote awareness about sexual violence, improve access of victims to report sexual violence to authorities and decisively prosecute perpetrators of sexual violence in agricultural communities.

\section{Conclusions}

Risky sexual behaviours like engagement in transactional sex, multiple sexual partnerships, poor condom use and sexual violence were highly prevalent among commercial farm workers. However, transactional sex was not significantly associated with 
HIV infection. Female sex, age 25 to 44 years, multiple sexual partnerships, recent history of sexually transmitted infection and sexual violence were significant risk factors for HIV infection. Combination HIV prevention interventions in farming communities should include behavioural change communication to reduce risky sexual behaviours, improved healthcare access for HIV and STI treatment and strengthening law enforcement against sexual violence.

\section{References}

1. UNAIDS. Prevention Gap Report. Geneva; 2016.

2. ILO. World Employment and Social Outlook: Trends 2019. Geneva; 2019.

3. IOM. HIV Integrated Biological and Behavioural Study (IBBSS). Pretoria; 2009.

4. IOM. Integrated Biological and Behavioral Surveillance Survey (IBBSS) South Africa. Pretoria; 2010.

5. Sateren WB, Foglia G, Renzullo PO, et al. Epidemiology of HIV-1 Infection in Agricultural Plantation Residents in Kericho, Kenya. JAIDS J Acquir Immune Defic Syndr 2006;43: 102-6.

6. Soko M, Moyo S, Rusinga O, Zvoushe A. Risk factors of HIV infection among farm workers at Rattray Arnold Research Farm in Goromonzi district, Zimbabwe: a qualitative study. African J AIDS Res 2015;14:343-51.

7. Shisana O, Rehle T, Simbayi LC, et al. South African National HIV Prevalence, Incidence and Behaviour Survey, 2012. Cape Town: HSRC Press; 2014.

8. Tiruneh K, Wasie B, Gonzalez H. Sexual behavior and vulnerability to HIV infection among seasonal migrant laborers in Metema district, northwest Ethiopia: a cross-sectional study. BMC Public Health 2015;15:122.

9. Ranganathan M, Heise L, Pettifor A, et al. Transactional sex among young women in rural South Africa: prevalence, mediators and association with HIV infection. J Int AIDS Soc 2016; 19:20749.

10. Giorgio M, Townsend L, Zembe Y, et al. Social Support, Sexual Violence, and Transactional Sex Among Female Transnational Migrants to South Africa. Am J Public Health 2016;106:1123-9.
11. Dana LM, Adinew YM, Sisay MM. Transactional Sex and HIV Risk among Adolescent School Girls in Ethiopia: Mixed Method Study. Biomed Res Int 2019;2019.

12. Ranganathan M, MacPhail C, Pettifor A, et al. Young women's perceptions of transactional sex and sexual agency: A qualitative study in the context of rural South Africa. BMC Public Health 2017;17:1-16.

13. Stoebenau K, Nixon SA, Rubincam C, et al. More than just talk: the framing of transactional sex and its implications for vulnerability to HIV in Lesotho, Madagascar and South Africa. Global Health 2011;7:34.

14. Jewkes R, Dunkle K, Shai MN and NJ. Transactional Sex and HIV Incidence in a Cohort of Young Women in the Stepping Stones Trial. J AIDS Clin Res 2012;03.

15. Phaswana-Mafuya N, Shisana O, Davids A, et al. Perceptions of sugar mommy practices in South Africa. J Psychol Africa 2014;24:257-63.

16. Stoebenau K, Heise L, Wamoyi J, Bobrova N. Revisiting the understanding of transactional sex in sub-Saharan Africa: A review and synthesis of the literature. 2016;

17. Wamoyi J, Stobeanau K, Bobrova N, et al. Transactional sex and risk for HIV infection in sub-Saharan Africa: a systematic review and meta-analysis. J Int AIDS Soc 2016;19:20992.

18. Oldenburg CE, Perez-Brumer AG, Reisner SL, et al. Global Burden of HIV among Men Who Engage in Transactional Sex: A Systematic Review and Meta-Analysis. Prestage G, editor. PLoS One. 2014;9:e103549.

19. Watt MH, Aunon FM, Skinner D, et al. Because he has bought for her, he wants to sleep with her: Alcohol as a currency for sexual exchange in South African drinking venues. Soc Sci Med 2012;74:1005-12.

20. Giorgio M, Townsend L, Zembe Y, et al. HIV Prevalence and Risk Factors Among Male Foreign Migrants in Cape Town, South Africa. AIDS Behav 2017;21:949-61.

21. Jewkes RK, Jewkes RK. Intimate partner violence, relationship power inequity, and incidence of HIV infection in young women in South Africa: a cohort study. Lancet 2010;376:41-8.
22. Ward H, Rönn M. Contribution of sexually transmitted infections to the sexual transmission of HIV. Curr Opin HIV AIDS 2010;5:305-10.

23. Francis SC, Mthiyane TN, Baisley K, et al. Prevalence of sexually transmitted infections among young people in South Africa: A nested survey in a health and demographic surveillance site. PLoS Med 2018;15:1-25.

24. Budlender D. Comparative Regional Integration Studies Migration and employment in South Africa: Statistical analysis of the migration module in the Quarterly Labour Force Survey, third quarter 2012 MiWORC Report. Johannesburg; 2014.

25. Camlin CS, Akullian A, Neilands TB, et al. Population mobility associated with higher risk sexual behaviour in eastern African communities participating in a Universal Testing and Treatment trial. J Int AIDS Soc 2018;21:e25115.

27. HSRC. South African National HIV Prevalence, Incidence and Behaviour Survey, 2012. Cape Town; 2014.

28. Shaffer DN, Ngetich IK, Bautista CT, et al. HIV-1 Incidence Rates and Risk Factors in Agricultural Workers and Dependents in Rural Kenya: 36-Month Follow-Up of the Kericho HIV Cohort Study. JAIDS J Acquir Immune Defic Syndr 2010;53:514-21.

29. Loevinsohn M. The 2001-03 famine and the dynamics of HIV in Malawi: A natural experiment. PLoS One 2015;10:1-21.

30. Kilburn K, Ranganathan M, Stoner $\mathrm{MCD}$, et al. Transactional sex and incident HIV infection in a cohort of young women from rural South Africa. AIDS 2018;32:1669-77.

31. Johnson LF, Hallett TB, Rehle TM, Dorrington RE. The effect of changes in condom usage and antiretroviral treatment coverage on human immunodeficiency virus incidence in South Africa: A model-based analysis. J R Soc Interface 2012;9:1544-54.

32. Madiba S, Ngwenya N. Cultural practices, gender inequality and inconsistent condom use increase vulnerability to HIV infection: narratives from married and cohabiting women in rural communities in Mpumalanga province, South Africa. Glob Health Action 2017;10: 1341597. 